\title{
Trends and Variability of Precipitation: Implications for Water Resources in Lake Ziway Watershed, Central Ethiopian Rift
}

\author{
WondimuTadiwos $^{1 *} \quad$ Tenalem Ayenew $^{2} \quad$ Sirak Tekleab $^{3} \quad$ N. K. Goel ${ }^{4}$ \\ 1.Addis Ababa University, College of Natural and Computational Sciences, African Center of Excellence for \\ Water Management \\ 2.Addis Ababa University, College of Natural and Computational Sciences, School of Earth Sciences \\ 3.Hawassa University, Faculty of Bio-systems and Water Resources Engineering, Department of Water \\ resources and Irrigation Engineering \\ 4.Department of Hydrology, Indian Institute of Technology Roorkee, Roorkee, India, 247667
}

\begin{abstract}
Precipitation is the significant climatic variable that governs the availability of water resources in the country, Ethiopia, but it is highly erratic and variable in spatial-temporal scales. The purpose of this paper was to analyse trends and variability of rainfall at seasonal to annual sales in the Ziway Lake Watershed. The non-parametric Mann-Kendall (MK) and Sen's Slope (SS) estimation were used to detect the trends and compute the magnitudes of slopes respectively. The Coefficient of Variation (CV) was employed to reveal the variations in rainfall. The spatial interpolations mapping was made by using IDW (Inverse Distance Weighting). The results revealed that the western Ziway Lake watershed had experienced more rainfall variability than the eastern Ziway Lake watershed. The results also indicated that the annual and summer rainfall did not exhibit significant evidence of a monotonic trend. On the other hand, almost all rainfall stations in the spring season revealed decreasing trends (significant and non-significant), for instance, there are three stations (Ogalcho, Butajira, and Koshe) showed significantly decreasing trends at $5 \%$ of significant level and the two stations (Kulumsa and Meki) indicates significantly decreasing trends at $10 \%$ significant level. Moreover, the magnitudes of slope (changes in $\mathrm{mm} / \mathrm{year}$ ) estimated by SS for stations in the spring season that display significantly decreasing trends were as follows: 8.702, - 6.58, -4.018, and -3.681,-3.667 for Butajira, Koshe, Kulumsa, Ogalcho, and Meki respectively. Droughts can be expected to increase if the decline precipitation trend continues. This could lead to over-exploitation of the water resources. The similarities in patterns of the intra-annual variability of precipitation and river discharges imply that any changes in rainfall pattern would have effects on water availability. The results of this investigation can significantly contribute to guiding water managers and decision-makers for more efficient water resources planning and management.
\end{abstract}

Keywords: Central Ethiopian Rift,, Ziway Lake Watershed, Precipitation, Variability, Trends

DOI: $10.7176 / \mathrm{JEES} / 10-10-03$

Publication date:October $31^{\text {st }} 2020$

\section{Introduction}

Precipitation is the primary source of surface water and groundwater, the changes in rainfall directly affect the total amount of water resources, and it is of considerable significance to analyse and study the characteristics and rules of changes of precipitation to improve the utilization of water resources (Yilinuer et al., 2020). Moreover, Wakachala et al. (2015) noted that rainfall variability is a crucial aspect of the climate regime of any place that affects crop and animal production, particularly in areas dependent on rain-fed cultivation systems. Rainfall data analysis can help provide information to assess climate risks, potential impacts, and better target attendant interventions in the Great Rift Valley of Kenya.

Ethiopian Rift Lakes are suffering from overexploitation of water and environmental changes; however, climatic changes play important role in changing the lake level (Legesse et al., 2004; Alemayehu et al., 2006). There are previous studies in the RVLB, linking the lakes level fluctuations to climatic variability (Ayenew, 2002; Wagesho et al., 2012; Jury, 2014; Belete et al., 2015; Seyoum et al., 2015), these imply that lakes are particularly vulnerable to climate variability due to their dependence on climatic variables such as precipitation, evaporation, and temperature.

The floor of the Ethiopian rift is occupied by a series of lakes fed by large perennial rivers originating from the highlands. The main source of water to the rift lakes and rivers is the rainfall in the eastern and western highlands (Ayenew, 2007). There have been some studies over Central Ethiopian Rift Lakes (CRV) examining precipitations variability and testing the temporal trends at annual bases (Seyoum et al., 2015; Bewketu and Ayenew, 2015; Takele et al. 2019). Therefore, the present study focused on the analysis of rainfall variability and trends at annual to seasonal scales. Moreover, the spatial distribution analysis through interpolation mapping has been included in order to understand the areal variations.

The analysis of the spatial and temporal distribution and changing patterns in rainfall is paramount important for the planning and management of water resources. This analysis is crucial to improve the utilization of water 
resources and for better understanding problems which indicate the causes that have been considered as indicative and visibly displaying the alarming situation.

\section{Materials and Methods}

\subsection{Description of the Study Area}

2.1.1 Geographical Location

This study focused on Lake Ziway watershed which is found in the Great East African Rift Valley lakes of Ethiopia and located geographically $38^{\circ} 0^{\prime} \mathrm{E} \& 39^{\circ} 30^{\prime} \mathrm{E}$ longitude and $7^{0} 15^{\prime} \mathrm{N} \& 8^{\circ} 30^{\prime} \mathrm{N}$ latitude and having a total geographical area of approximately $7300 \mathrm{Km}^{2}$. The lake is found in the Rift Valley Lakes Basin (RVLB) which is one of 12 basins in Ethiopia (Figure 1). This Lake is the freshest water lake among the rift lakes in Ethiopia (MoWR, 2010).

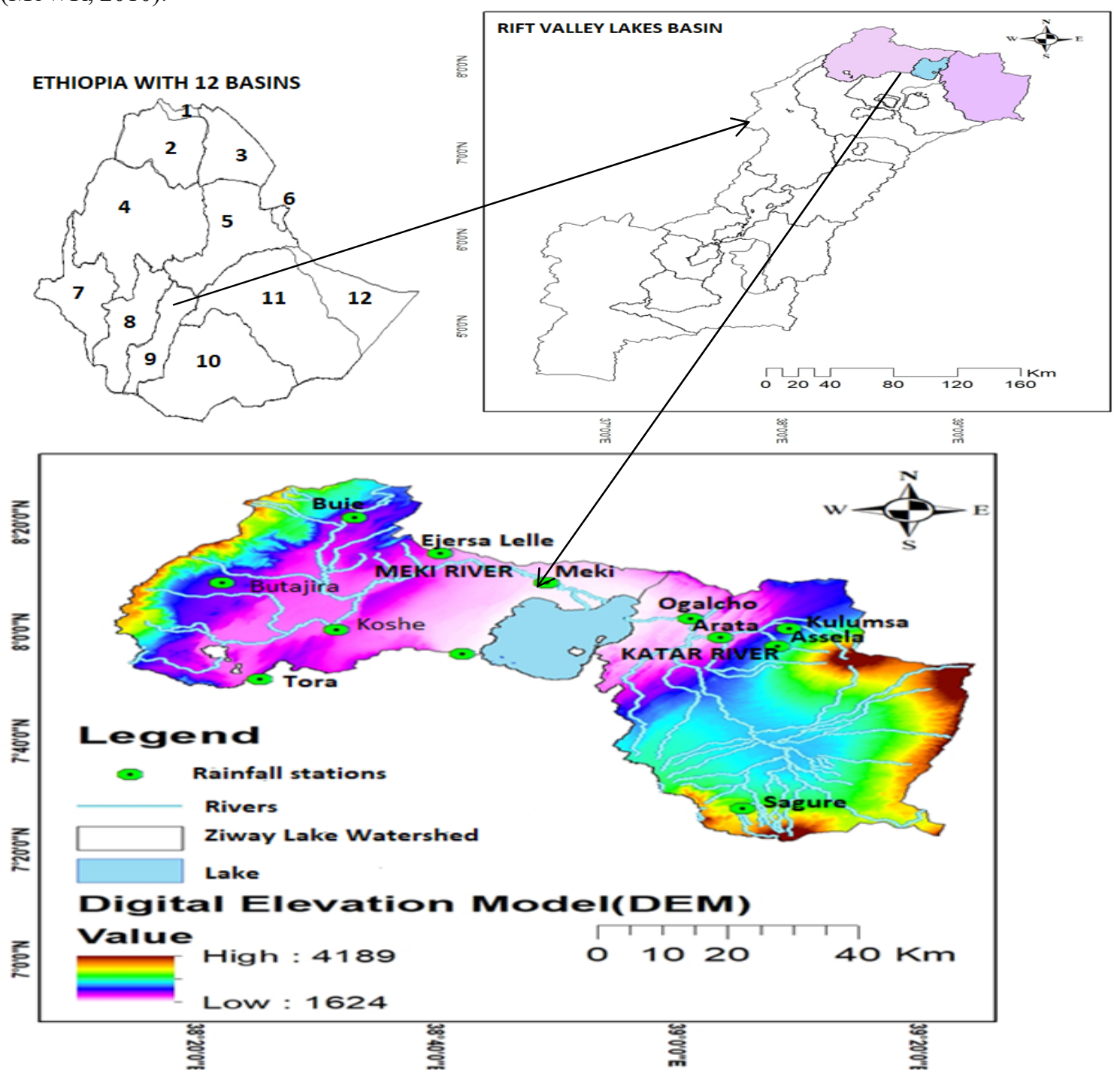

Figure 1: Location map showing the lake Ziway and its watersheds, Topographic feature based on DEM, Rainfall Stations, Rivers, the Rift Valley Lakes Basin and Ethiopia with 12 basins (1=Mereb, 2= Tekeze, 3=Denakil, 4=Abbay, 5=Awash, 6=Ayisha, 7=Baro Akobo, 8=Omo Gibe, 9=Rift Valley, 10=Genale Dawa, 11=Wabi Shebelle and $12=$ Ogaden).

2.1.2 Topographic Features and Climate of the Study Area

The catchments of Ziway-Abijata Lakes have three physiographic regions: the rift floor, escarpment, and highland. The climate is humid to sub-humid in the highlands and semi-arid in the rift valley. The mean annual temperature is around $15^{\circ} \mathrm{C}$ in the highlands and $20^{\circ} \mathrm{C}$ in the rift valley (Ayenew, 2002). The topographic feature using the Shuttle Radar Topography Mission Digital Elevation Model (SRTM DEM) with 30m resolution (https://www.usgs.gov/) for Ziway Lake and its catchment is shown in Figure 1. The maximum and minimum heights within the GIS topographic map area are 4189 and 1624 (m.a.s.l) respectively (Figure 1). The highest points are located in the Eastern Arsi and Western Gurage Mountains respectively whereas the lowest point is in 
the rift floor close to the lake. From Figure 1, we can observe that the highlands are the sources of the main rivers (Meki and Katar) which are flowing into Lake Ziway.

Ethiopia's rainfall climatology is determined mainly by seasonal changes in large-scale circulation, part of which involves the seasonal north-south movement of the intertropical convergence zone (ITCZ) (Korecha and Barnston, 2007). The passage of the ITCZ gives rise to the bimodal rainfall pattern in southern Ethiopia (Belg and October, November, December), and the monomodal pattern in the north (Kiremt) (Diro et al., 2008).

Based on the time series data from 1985 to 2015, the study area receives annual rainfall between $598 \mathrm{~mm}$ and $1091 \mathrm{~mm}$ with an average of $813 \mathrm{~mm}$. The average monthly rainfall is $182.84 \mathrm{~mm}$ for the wettest month (July) and $8.07 \mathrm{~mm}$ for the driest month (December). The study area is characterized by a mono-modal pattern with one rainfall maximum i.e. July (Figure 2). In this study, the seasonal analyses of rainfall were carried out for summer (June-September) which is locally called the Kiremt rainfall season, and for spring (February-May) which is locally called the Belg rainfall season.

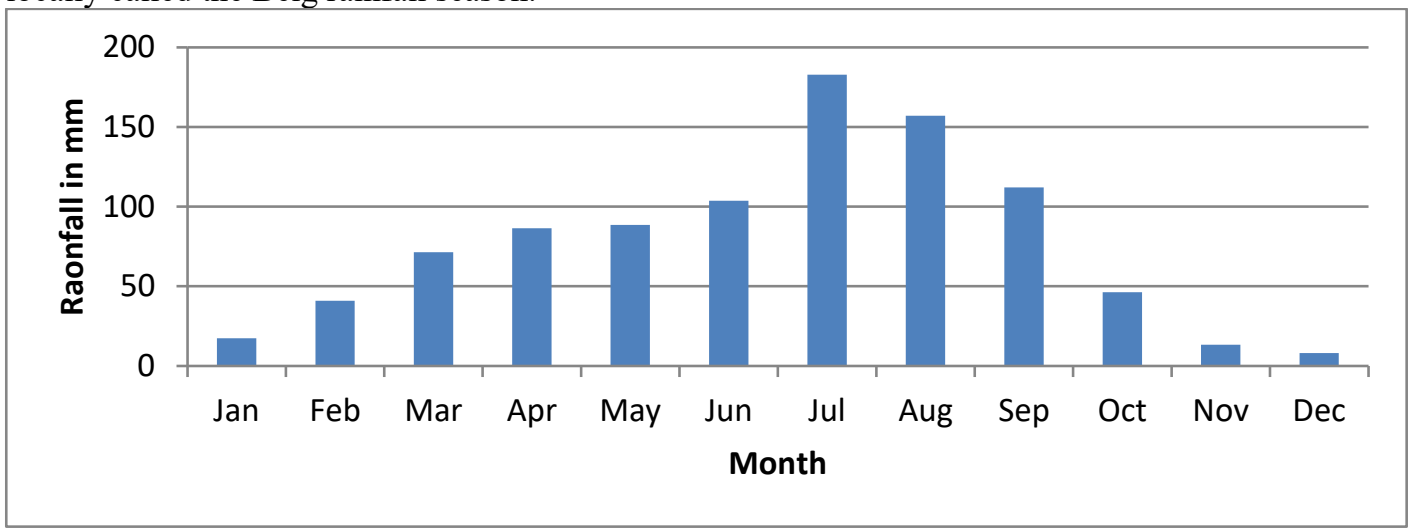

Figure 2: Monthly mean precipitation of Ziway watersheds for the period of 1985-2015

\subsection{Data and Methodology}

\subsubsection{Datasets}

Meteorological and hydrological time series data were sampled from the National Meteorological Agency (NMA) and the Ministry of Water, Irrigation, and Energy (MoWIE) respectively. The spatial distribution of the rainfall stations indicated in Figure 1. In developing countries hydrometric networks are limited (Raphael et al., 2011; Maxime et al., 2012) and hence the rain gauges are sparsely and unevenly distributed primarily over the study area and there are missing values for the available collected data for a few stations. Moreover, Dink (2019) also noted that existing stations in the country, Ethiopia, are unevenly distributed with most of the stations located in cities and towns along the main roads.

Hence, in this paper, the missing values with less than $10 \%$ have been estimated by using Correlation Coefficient Weighting (CCW) (Teegavarapu, 2009; Michael et al., 2012; Alonso et al., 2018). In this approach, missing data from target station are determined from the values observed in neighboring stations weighted by the Pearson's correlation coefficient between the target and the neighboring stations.

The missing value $\mathrm{Y}_{\mathrm{j}}$ in a given month at the target station $\mathrm{m}$ is completed as:

$Y_{j(m)}=\frac{\sum_{i=1}^{n} r_{m i} \cdot x_{j(i)}}{\sum_{i=1}^{n} r_{m i}}$

Where, $r_{m i}$ is the Pearson's correlation coefficient between the precipitation series of the neighboring station $\mathrm{i}$ and the incomplete series of the target station $\mathrm{m}, x_{j(i)}$ is the rainfall value observed at station $\mathrm{i}$.

2.2.2 Mann-Kendall (MK) test

The non-parametric Mann-Kendall is a useful nonparametric technique to analyse the significance of monotonic trends in hydro-meteorological variables (Mann, 1945; Kendall, 1975). It is the most common trend analysis and applicable in several studies (e.g. Love et al., 2010; Tesemma et al., 2010; Tekleab et al., 2013; Belihu et al., 2018). Therefore, in this study, the MK test was employed to investigate the presence of significant trends for meteorological variable i.e., precipitation.

The MK test checks the null hypothesis of no trend versus the alternative hypothesis of the existence of increasing or decreasing trend. The null hypothesis $\mathrm{H}_{0}$ is that a sample of data $\left\{X_{i}, i=1,2 \ldots n\right\}$ is independent and identically distributed. The alternative hypothesis $\mathrm{H}_{1}$ is that a monotonic trend exists in $\mathrm{X}$.

The Mann-Kendall test statistics $S$ is calculated from the following equation:

$S=\sum_{k=1}^{n-1} \sum_{j=k+1}^{n} \operatorname{sgn}\left(X_{j}-X_{k}\right)$, where 
$\operatorname{sgn}\left(X_{j}-X_{k}\right)=\left\{\begin{array}{c}+1 \text { if }\left(X_{j}-X_{k}\right)>0 \\ 0 \text { if }\left(X_{j}-X_{k}\right)=0 \\ -1 \text { if }\left(X_{j}-X_{k}\right)<0\end{array}\right.$.

where $n$ is the number of observations. For independent and randomly ordered data for large $n$, the $S$ statistics approximate a normal distribution with mean $E(S)=0$ and a variance, $\mathrm{V}(\mathrm{S})$ is calculated as:

$(S)=\frac{n(n-1)(2 n+5)-\sum_{m=1}^{n} t_{m} m(m-1)(2 m+5)}{18}$

where $t_{\mathrm{m}}$ is the number of ties of extent $\mathrm{m}$. The significance of a trend is tested by comparing the standardized test statistics $Z$ with the standard normal cumulative distribution at a selected significance level.

$Z=\left\{\begin{array}{l}\frac{s-1}{\sqrt{\operatorname{var}(s)}} \text { if } S>0 \\ 0 \quad \text { if } S=0 \\ \frac{S+1}{\sqrt{\operatorname{var}(S)}} \text { if } S<0\end{array}\right.$

In the equation (4), positive values of $Z$ statistics indicate a positive trend (an increasing trend), while negative $\mathrm{Z}$ values indicate a decreasing trend. If the standardized statistic $|\mathrm{Z}|>2.58$, the trend is significant at the $99 \%$ confidence level; if the standardized statistic $|Z|>1.96$, the trend is significant at the $95 \%$ confidence level; if the standardized statistic $|Z|>1.65$, the trend is significant at the $90 \%$ confidence level, and vice versa (Farlie, 1971). For example, the null hypothesis of no-trend is rejected, and alternative hypothesis of significant trend is accepted, if it is tested at $95 \%$ confidence level. It means that the trend is statistically significant at $\alpha=95 \%$ when the absolute value of $Z$ is higher than 1.96 .

2.2.3 Sen's Slope (SS) Estimator

In addition to trend detection, it is essential to estimate the trend magnitude. Therefore, The slope of rainfall (i.e., change in rainfall over time) was estimated by using Sen's Slope Estimator developed by Sen (1968) which was applied in various studies (eg., Kumar et al., 2009; Khattak et al., 2011; Abiyot and Dwarkish, 2020). It is a nonparametric method, assuming that it follows a linear trend of the form $\mathrm{f}(\mathrm{t})=\mathrm{Qt}+\mathrm{B}$, where ' $\mathrm{Q}$ ' is the trend given by the slope in units time, ' $\mathrm{B}$ ' is the intercept and ' $\mathrm{t}$ ' is the time.

Here, the slope $\left(\mathrm{Q}_{\mathrm{i}}\right)$ of all data pairs is computed as:

$Q_{\mathrm{i}}=\frac{\mathrm{x}_{\mathrm{j}}-\mathrm{x}_{\mathrm{k}}}{\mathrm{j}-\mathrm{k}}$

for $\mathrm{i}=1,2 \ldots, \mathrm{N}$, where $\mathrm{X}_{\mathrm{j}}$ and $\mathrm{X}_{\mathrm{k}}$ are considered as data values at time $\mathrm{j}$ and $\mathrm{k}(\mathrm{j}>\mathrm{k})$ correspondingly.

The median of these $\mathrm{N}$ values of $\mathrm{Q}_{i}$ 's represented as Sen's estimator of slope which is given as:

$Q_{i}=\left\{\begin{array}{c}\frac{Q_{N+1}}{2} \quad N \text { is odd } \\ \frac{1}{2}\left(Q_{\frac{N}{2}}+Q_{\frac{N+2}{2}}\right) N \text { is even }\end{array}\right.$

Positive value of $\mathrm{Q}_{i}$ indicates an upward or increasing trend and a negative value of $\mathrm{Q}_{i}$ gives a downward or decreasing trend in the time series.

2.2.4 Precipitation Variability Analysis

Coefficient of variation $(\mathrm{CV})$ is a measure of how the individual data points vary about the mean. A greater value of CV is the indicator of larger variability, and vice versa. According to Hare (1983), CV is used to classify the degree of variability of rainfall events as less, moderate and high. When $\mathrm{CV}<20 \%$ it is less variable, CV from $20 \%$ to $30 \%$ is moderately variable, and CV $>30 \%$ is highly variable. Areas with CV $>30 \%$ are said to be vulnerable to drought. This can be applied in various studies (Teyso et al., 2016; Tamirat, 2018; Zannat et al., 2019). Therefore, in this study CV was used to identify the variations in annual and seasonal rainfall. It is estimated by the Eq. (6)

$C V=\frac{S}{\mu} \times 100$

Where, $\mathrm{CV}$ is the coefficient of variability, $\mathrm{S}$ is standard deviation and $\mu$ is mean.

2.2.5 Spatial Distribution Analysis

Most meteorological data in Ethiopia is inconsistent, unrecorded, or missing, leading to more discrete and unreliable datasets for analysis, this request for use of data reconstruction through interpolation methods (Suryabhagavan, 2017). Therefore, in this paper, mapping the spatial annual to seasonal variability of precipitation in the catchments was analysed by using the Inverse Distance Weighting (IDW) interpolation. The computation was made by using ArcGIS software. Lu and Wong (2008) noted that the IDW method was used to interpolate spatial distribution of rainfall. It is based on the assumption that the weighted average of known values within the neighborhood is used to estimate the value of a non-sampled point. Moreover, Zannat et al. (2019) also pointed out that IDW is a very flexible spatial interpolation method. It is easy to use to interpolate spatial distribution. 


\section{Results and Discussion}

\subsection{Analysis of Annual and Seasonal Rainfall Variability}

In this study, the coefficient of variability (CV) was calculated for the annual and seasonal rainfalls in order to see how variable they are. From table 1, in annual rainfall, we can observe that the percentage of CV is ranging from $11.7 \%$ (Kulumsa)-29.9\%(Butajira and Ogalcho) per year. In the summer season, there are only two stations categorized under highly variable, namely Butajira(30.6\%) and Ogalcho(38.7\%). The spring season is highly variable $(\mathrm{CV}>30)$ for all rainfall stations. The greater rainfall variability and more chances of occurrence of drought can be associated with the high value of $\mathrm{CV}$.

Table 1: The values of Coefficients Variability (CV) for annual, summer and spring season rainfalls

\begin{tabular}{|c|c|c|c|c|c|c|}
\hline \multirow[t]{2}{*}{ Station } & \multicolumn{2}{|c|}{ Annual Rainfall } & \multicolumn{2}{|c|}{ Summer Rainfall } & \multicolumn{2}{|c|}{ Spring Rainfall } \\
\hline & $\begin{array}{l}\text { CV } \\
(\%)\end{array}$ & Classification & $\begin{array}{l}\text { CV } \\
(\%)\end{array}$ & Classification & $\begin{array}{l}\text { CV } \\
(\%)\end{array}$ & Classification \\
\hline Asella & 14.5 & Less Variable & 15.0 & Less Variable & 34.7 & $\begin{array}{l}\text { Highly } \\
\text { Variable }\end{array}$ \\
\hline Butajira & 29.9 & $\begin{array}{l}\text { Moderately } \\
\text { variable }\end{array}$ & 30.6 & Highly Variable & 53.9 & $\begin{array}{l}\text { Highly } \\
\text { Variable }\end{array}$ \\
\hline Sagure & 15.1 & Less Variable & 18.8 & Less Variable & 37.9 & $\begin{array}{l}\text { Highly } \\
\text { Variable }\end{array}$ \\
\hline Ziway & 20.1 & $\begin{array}{l}\text { Moderately } \\
\text { variable }\end{array}$ & 26.5 & $\begin{array}{l}\text { Moderately } \\
\text { variable }\end{array}$ & 45.2 & $\begin{array}{l}\text { Highly } \\
\text { Variable }\end{array}$ \\
\hline Kulumsa & 11.7 & Less Variable & 18.0 & Less Variable & 35.7 & $\begin{array}{l}\text { Highly } \\
\text { Variable }\end{array}$ \\
\hline Arata & 17.9 & Less Variable & 25.7 & $\begin{array}{l}\text { Moderately } \\
\text { variable }\end{array}$ & 40.5 & $\begin{array}{l}\text { Highly } \\
\text { Variable }\end{array}$ \\
\hline Ogalcho & 29.9 & $\begin{array}{l}\text { Moderately } \\
\text { variable }\end{array}$ & 38.9 & Highly Variable & 40.8 & $\begin{array}{l}\text { Highly } \\
\text { Variable }\end{array}$ \\
\hline Ejersa Lelle & 21.9 & $\begin{array}{l}\text { Moderately } \\
\text { variable }\end{array}$ & 27.3 & $\begin{array}{l}\text { Moderately } \\
\text { variable }\end{array}$ & 42.9 & $\begin{array}{l}\text { Highly } \\
\text { Variable }\end{array}$ \\
\hline Buei & 21.1 & $\begin{array}{l}\text { Moderately } \\
\text { variable }\end{array}$ & 19.1 & Less Variable & 51.6 & $\begin{array}{l}\text { Highly } \\
\text { Variable }\end{array}$ \\
\hline Meki & 22.4 & $\begin{array}{l}\text { Moderately } \\
\text { variable }\end{array}$ & 26.7 & $\begin{array}{l}\text { Moderately } \\
\text { variable }\end{array}$ & 47.1 & $\begin{array}{l}\text { Highly } \\
\text { Variable }\end{array}$ \\
\hline Koshe & 24.3 & $\begin{array}{l}\text { Moderately } \\
\text { variable }\end{array}$ & 26.2 & $\begin{array}{l}\text { Moderately } \\
\text { variable }\end{array}$ & 52.4 & $\begin{array}{l}\text { Highly } \\
\text { Variable }\end{array}$ \\
\hline
\end{tabular}

\section{CV= Coefficient of Variability}

The spatial interpolations maps for annual and seasonal rainfalls have shown in figures 3,4 , and 5 . The interpolations were made by using the deterministic method i.e., IDW. From these figures, we can observe that the western Ziway Lake watershed (Meki River watershed) had experienced more rainfall variability in annual and seasonal rainfalls than the eastern Ziway Lake watershed (Katar River watershed). Moreover, in Figure 5, it can be seen that the large portions of variability are accounted for during the short rainfall season (spring) which is ranging from $34.7-53.9 \%$. This result consistent with a study conducted by (Seleshi and Zank, 2004; Diro et al., 2008; Suryabhagavan, 2017) and they concluded that the spring rainfall is highly variable in Ethiopia. The analysis of the coefficient of variability also showed that rainfall in this study area was erratic for the last 31 years (19852015). 


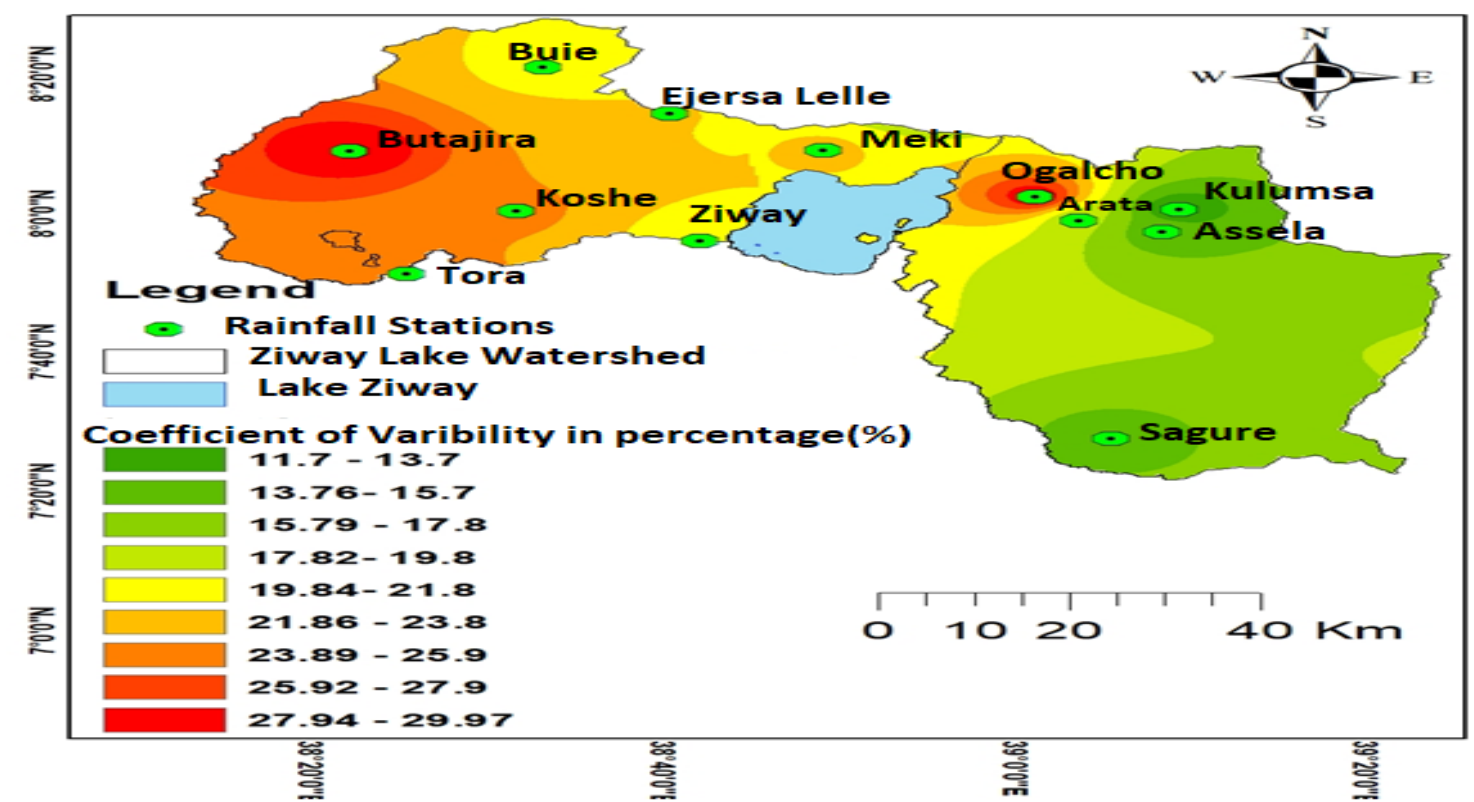

Figure 3: The spatial annual rainfall variability based on the values of $\mathrm{CV}$ in the study area

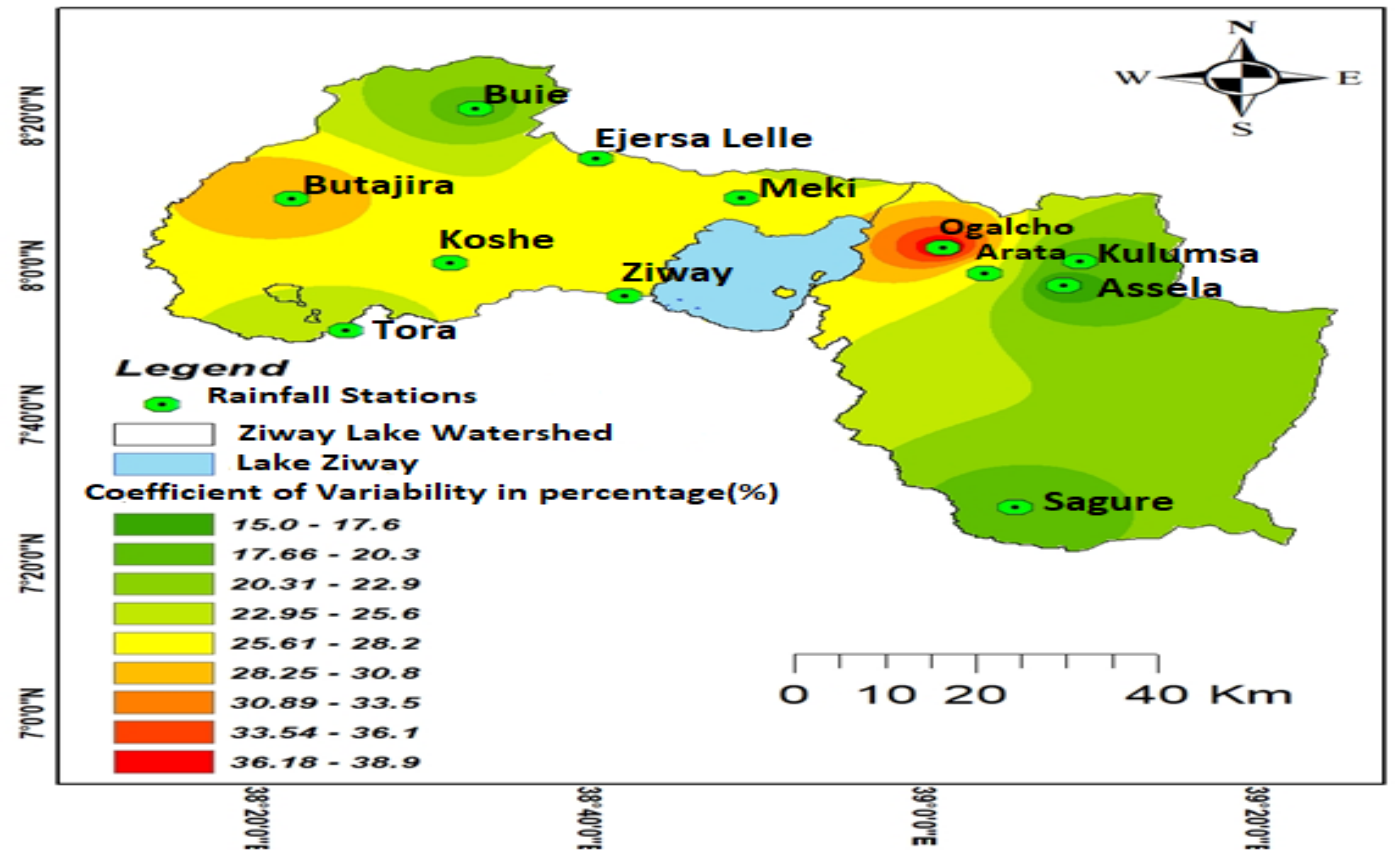

Figure 4: The spatial summer rainfall variability based on the values of CV in the study area 


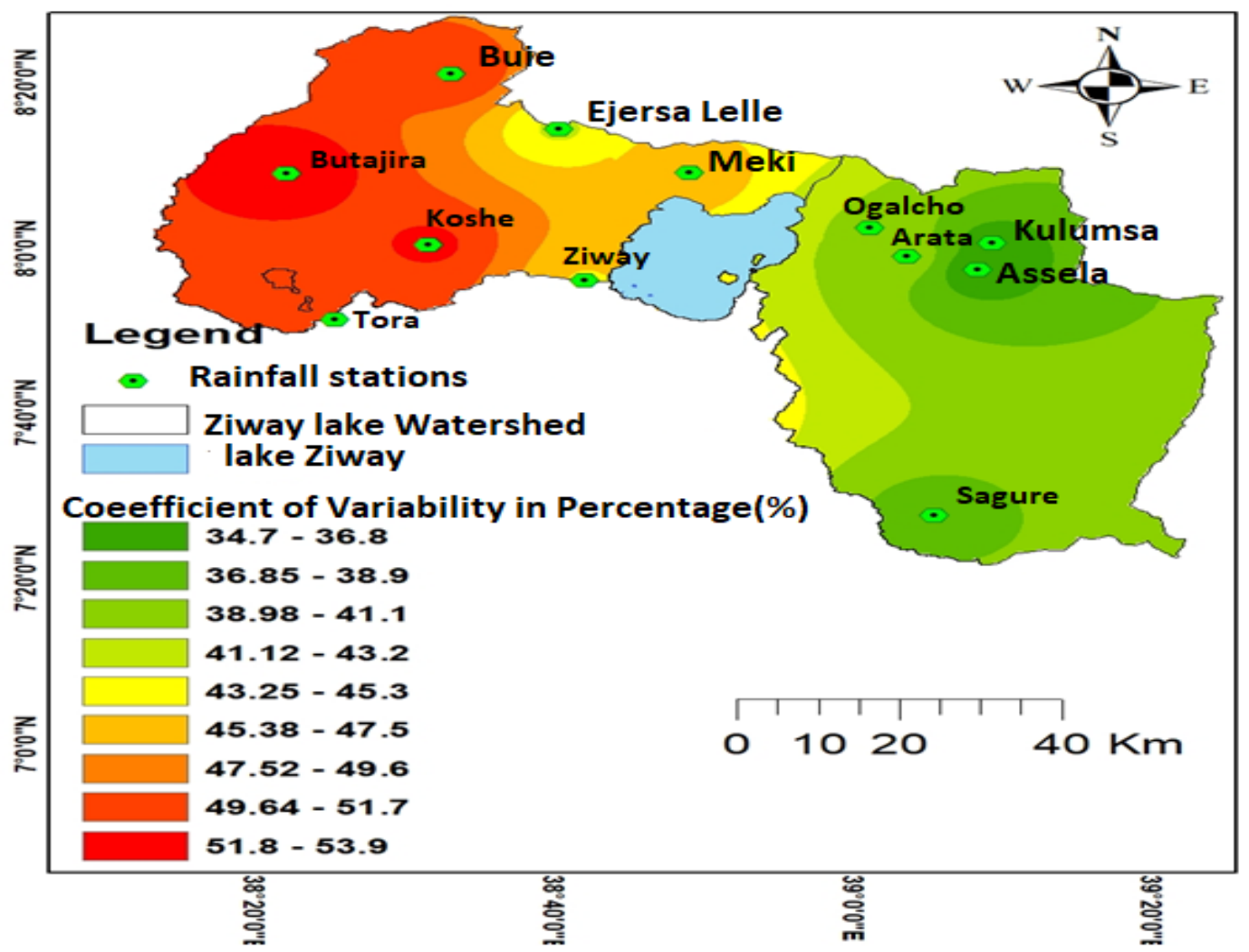

Figure 5: The spatial spring rainfall variability based on the values of $\mathrm{CV}$ in the study area

\subsection{Trend Analysis}

As indicated in Table 2, the annual rainfall for all stations doesn't show any significant decreasing or increasing trends. This analysis is also consistent with the previous study conducted by (Seyoum et al., 2015; Bewketu and Ayenew, 2015; Takele et al., 2019). They concluded that there were no statistically significant trends at the annual base in the study area. In Table 2, we can observe that out of 11 stations, 7 are decreasing trends in annual base although they are statically non-significant. Moreover, in this table, it can be observed that in the summer season (long rainy season), out of 11 rainfall stations, 7 are non-significantly increasing trends. The increased total summer rainfalls suggest the increasing importance of freshwater storage in the lake and water harvesting in the area.

On the other hand, regarding the spring season (the short rainfall season) almost all rainfall stations shows more negative than positive trends across the catchments. Based on MK tests, there are three stations that indicate statistically significant a decreasing trend at a 95\% confidence level during the spring season. These are Ogalcho, Butagira, and Koshe. Moreover, Meki and Kulumsa rainfall stations show statistically significant decreasing trends at a $90 \%$ confidence level during this season.

Sen's Slope(SS) is also demonstrating increasing and decreasing magnitude of slope in correspondence with the MK Test values. For example, in table 5, we can observe that for the rainfall stations in the spring season that display the significant decreasing trends. Moreover, the magnitudes of slope (changes in mm/year) estimated by SS for rainfall stations in the spring season that display significantly decreasing trends were as follows:

$-8.702,-6.58,-4.018,-3.681$ and -3.667 for Butajira, Koshe, Kulumsa, Ogalcho, and Meki respectively. The results suggest a decreasing rainfall showed more drying conditions (drought) within the catchments of Ziway Lake. That makes the area more prone to drought conditions. 
Table 2: Applying MK and SS statistic trends tests for detecting the significance of the trends for annual and seasonal rainfall for the period of 1985-2015 (31years).

\begin{tabular}{|c|c|c|c|c|}
\hline $\begin{array}{l}\text { Rainfall Station } \\
\text { name }\end{array}$ & Trend Tests & Annual Rainfall Trends & Belg(Spring) Rainfall Trends & $\begin{array}{l}\text { Kiremt(Summer) } \\
\text { Rainfall Trends }\end{array}$ \\
\hline \multirow[t]{2}{*}{ Kulumsa } & MK & -0.646 & $-1.699 *$ & 0.459 \\
\hline & SS & -1.075 & -4.018 & 0.572 \\
\hline \multirow[t]{2}{*}{ Assella } & MK & -0.272 & -0.884 & 0.204 \\
\hline & SS & -0.611 & -1.86 & 0.3 \\
\hline \multirow[t]{2}{*}{ Arata } & MK & -0.136 & -1.598 & -0.136 \\
\hline & $\mathrm{SS}$ & -0.483 & -2.87 & -0.13 \\
\hline \multirow[t]{2}{*}{ Ogalcho } & MK & -1.39 & $-2.074 * *$ & -0.272 \\
\hline & $\mathrm{SS}$ & -5.436 & -3.681 & -0.838 \\
\hline \multirow[t]{2}{*}{ Butajira } & MK & -0.748 & $-2.312 * *$ & 0.408 \\
\hline & $\mathrm{SS}$ & -5.947 & -8.702 & 2.083 \\
\hline \multirow[t]{2}{*}{ Buei } & MK & 0.952 & -0.238 & 1.224 \\
\hline & $\mathrm{SS}$ & 3.9 & -1.017 & 3.172 \\
\hline \multirow[t]{2}{*}{ Meki } & MK & -0.782 & $-1.836^{*}$ & -0.952 \\
\hline & SS & -2.35 & -3.667 & -1.804 \\
\hline \multirow[t]{2}{*}{ Ziway } & MK & 1.122 & -1.224 & 1.156 \\
\hline & SS & 4.024 & -2.94 & 2.68 \\
\hline \multirow[t]{2}{*}{ Koshe } & MK & -1.461 & $-2.31 * *$ & -0.815 \\
\hline & $\mathrm{SS}$ & -6.531 & -6.58 & -2.57 \\
\hline \multirow[t]{2}{*}{ Ejerssa Lelle } & MK & 0.884 & -0.679 & 1.122 \\
\hline & $\mathrm{SS}$ & 3.3375 & -1.24 & 3.04 \\
\hline \multirow[t]{2}{*}{ Sagure } & MK & 0.068 & 0.102 & 1.189 \\
\hline & SS & 0.574 & 0.255 & 1.897 \\
\hline
\end{tabular}

Siginificant at $\mathrm{P}<0.10^{*}, \mathrm{P}<0.05^{* *}$ and $\mathrm{P}<0.0$. Here we noted that $* * *, * * *$, indicate at $10 \%, 5 \%$, and $1 \%$, significant levels respectively.

\subsection{Water Resources Implications}

The agricultural activities in Ethiopia are mainly rain-fed and hence understanding the spatial and temporal variability of precipitation is paramount important. Droughts can be expected to increase if the decline of precipitation trend continues. This could lead to increased human influences based on the high abstraction of water (water is withdrawn) for irrigation practice (agricultural activities) from the lake and Feeder Rivers.

The previous studies conducted by (Halcrow \& Partners, 1989; Legesse et al., 2004; Seyoum et al., 2015), noted that human abstraction (industrial and agricultural) from the lakes and the tributaries in the Ethiopia Central Rift Valley started in the early 1980s and has increased with time. Moreover, Zinabu and Elias (1989) concluded that the irrigation in Lake Ziway watershed is a year-round process; its effect on the water level is magnified, especially during times of low precipitation.

Meki and Katar rivers are the main inflow into Lake Ziway whereas Bulbula River is the outflow of Ziway Lake. Figures 6 and 7 depict the intra-annual variability of precipitation and river discharges in the period of 19802010. Hence, the main rivers (Meki and Katar) in the catchments show in a similar pattern with the areal precipitations. Both are larger in the rainy season i.e. from June-September (JJAS). The similarities in patterns in the river discharges and rainfall indicated that rainfall as inputs for the hydrological cycle (precipitation-driven hydrologic processes). 


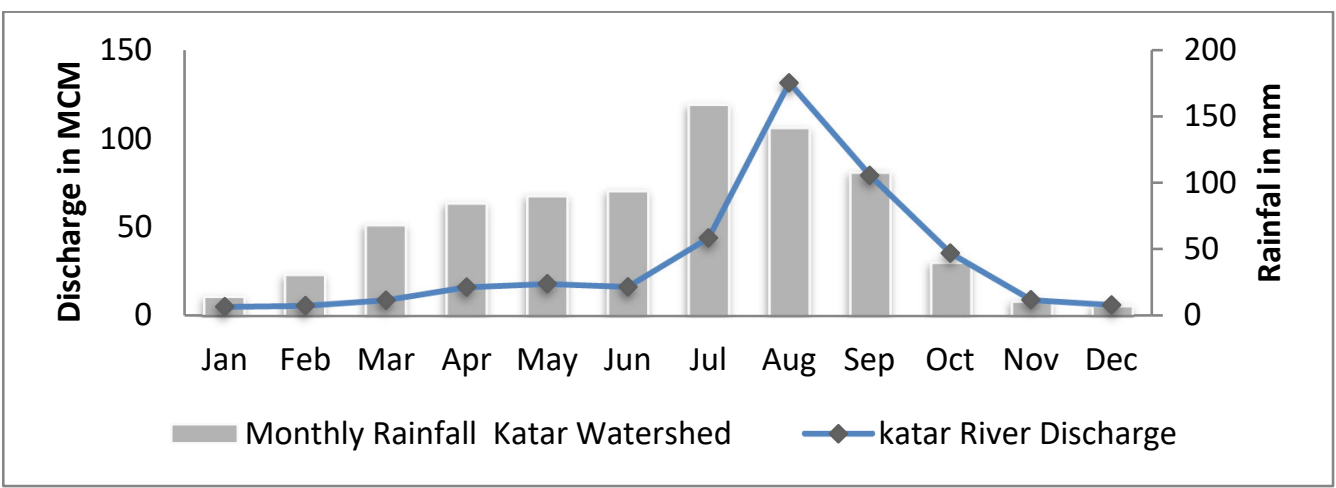

Figure 6: Intra-annual distributions of stream flow and precipitation in Katar Watershed (Eastern Ziway Lake) from 1980-2010

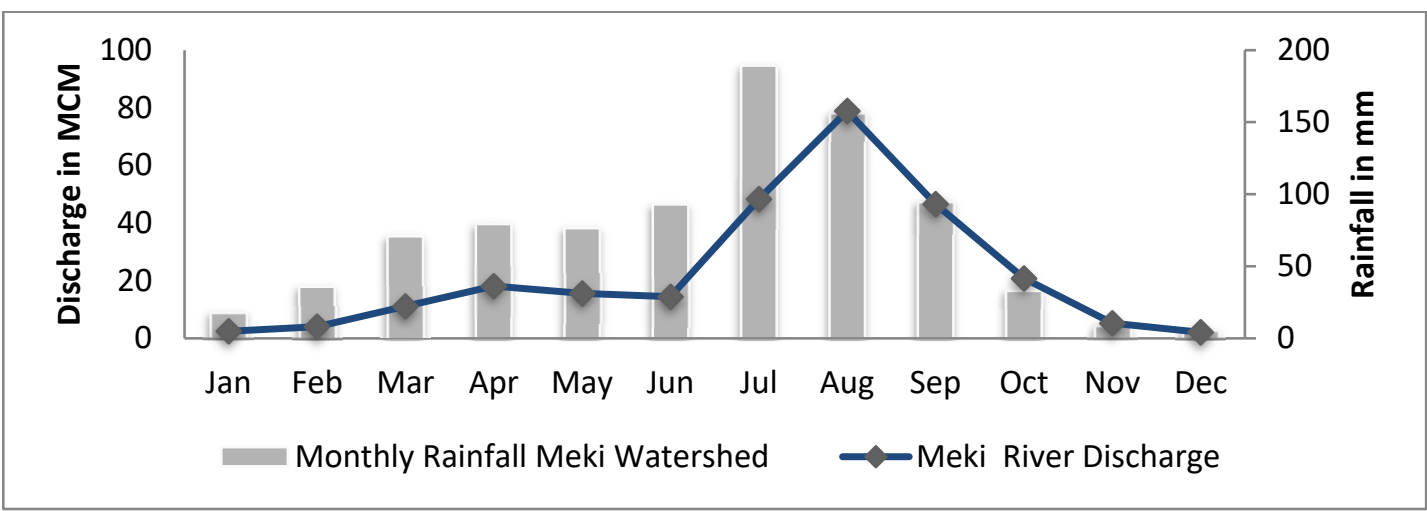

Figure 7: Intra-annual distributions of stream flow and precipitation in Katar Watershed (Eastern Ziway Lake) from 1980-2010.

The Ziway Lake receives water flows mainly from two rivers: Meki and Katar and discharges into the Bulbula River from a narrow outlet in the south of the lake (see Figure 8). Bulbula River is the outflow of Lake Ziway and drains into Lake Abijata. It drains in the catchment of Abijata Lake and its flows depend on the water level of Ziway Lake. Bulbula River is the main source water for Abijata Lake but currently, this river is diminished due to the high abstraction of water for irrigation and industrial water uses.

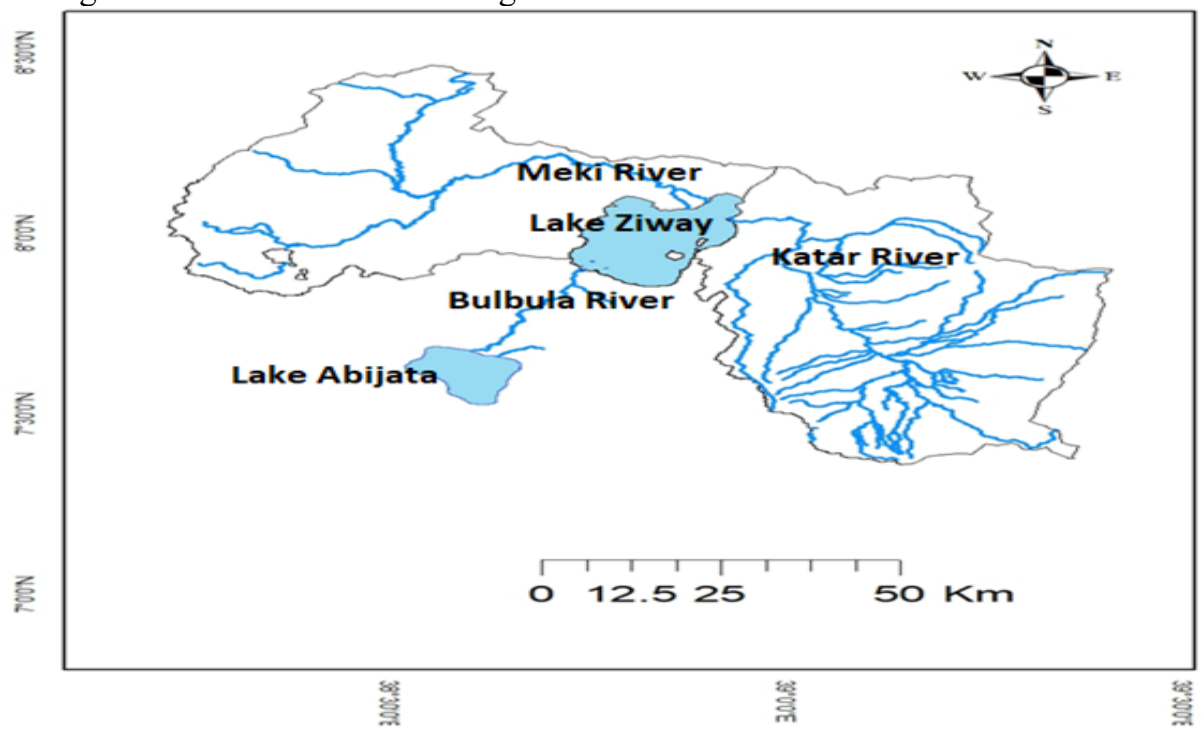

Figure 8: The hydrological connection of Lakes Ziway and Abijata via Bulbula River.

Figure 9 depicts the intra-annual variability of the Ziway Lake water level and Bulbula River discharges. They are highly interrelated. From this figure, we can also observe that the water level of Ziway Lake and Bulbula River are enlarged during the long rainy season (summer). Inconsistency of rainfall is one of the factors which govern the degradation of the lake and Feeder Rivers since the water abstraction is common during low rainfall season. It is important to use a rainwater harvesting system which is the collection of runoff for productive use 
during low rainfall months.

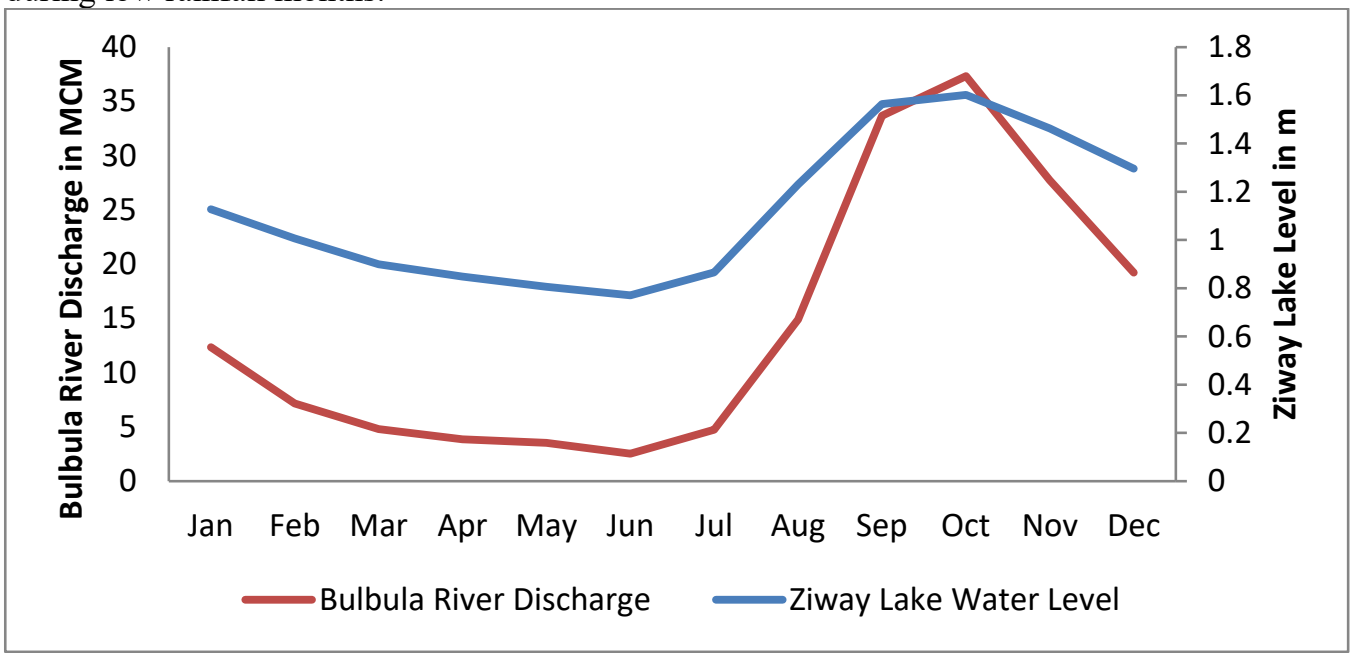

Figure 9: The Mean Monthly fluctuation of Ziway Lake water level and Bulbula River for the period of 19802010.

The irrigated areas in the Ethiopian CRV are sustained by abstracting the higher amount of water from Lake Ziway (up to $31 \%$ ) than other water resources like the Katar River (27\%), groundwater (25\%), Meki River (11\%), Bulbula River (4\%) and spring water (2\%) (Ester, 2010). Hence, Ziway Lake has been extensively exploited during the past decades due to irrigation water abstraction.

According to the water user inventory report during 2016, there were 5202 motor pumps with different sizes and discharge rates counted in catchments of Ziway and Abijata lakes (RVLBA, 2016). The majority of them were located in the vicinity of Lake Ziway. Moreover, in the study conducted by Ayenew(2002), the depth of groundwater close to Ziway Lake was in the range of 2-3 m, but recently it becomes greater than 5m(RVLBA, 2016). This implies that the lake has also been exploited due to intensive groundwater pumping activities. The main recharge zone of the Abijata Lake is the watersheds of Lake Ziway. However, the Ziway lake recharge zone or has fallen prey to encroachment and groundwater abstractions. Therefore, Legesse and Ayenew (2006) investigated that the rift lakes are interconnected with surface and subsurface waters.

\section{Conclusions}

The Ethiopian Rift Valley Lakes have been reported to be deteriorating in the recent past. The inflows to the lakes and their feeder rivers have also reduced and the water resources have become environmentally very vulnerable. Due to the fact that the study area is under precipitation-driven hydrologic processes, it is very crucial to study and understand the rainfall trends and variability. Rainfall variability is an important aspect of the climate regime of any place. In this study Coefficient of Variation (CV) was used to identify the variations in annual and seasonal rainfall. The spatial interpolations mapping has shown that the western Ziway Lake watershed (Meki River watershed) had experienced more rainfall variability in annual and seasonal rainfalls than the eastern Ziway Lake watershed (Katar River watershed). The analysis also revealed that almost all rainfall stations exhibit highly variable during the spring season with the CV values greater than $30 \%$.

In this study, the non-parametric Mann-Kendall (MK) and Sen's Slope (SS) statistic tests were applied to assess the significance of the trends in the precipitation variability at annual and seasonal scale (summer and spring season). The MK test indicates that the annual and summer rainfall doesn't show any significant trends for all stations. But in the spring season, there are three rainfall stations that show significantly decreasing trends at $5 \%$ of a significant level. These stations are Ogalcho, Butajira, and Koshe. Moreover, significantly decreasing trends observed at a 10\% significant level for two stations, namely, Kulumsa and Meki. The remaining stations revealed that no clear significant trends. Moreover, the magnitudes of slope (changes in $\mathrm{mm} / \mathrm{year}$ ) estimated by SS for rainfall stations in the spring season that display significantly decreasing trends were as follows: $-8.702,-6.58,-$ 4.018, -3.681, and -3.667 for Butajira, Koshe, Kulumsa, Ogalcho, and Meki respectively.

In general, the spring seasons rainfall showed highly variable and decreasing trends. This leads to higher exploitation of surface water (lakes and rivers) and groundwater during this season. The results also revealed that the observed deteriorations in water resources over the last few decades are the consequences of both climatic and human activities. These findings may contribute to complement the understanding of the roles precipitations variability and trends for the deterioration of the lakes and Feeder Rivers. It can be suggested for further studies to consider the variability of hydrological parameters (precipitation, streamflow, and lake water level) linking with the large-scale modes of climate signals. 


\section{References}

Abiot, K. Dwarakish, G.S. (2020), "Trend and variability of hydrometeorological variables of Tikur Wuha watershed in Ethiopia.", Arabian Journal of Geosciences. 13. 142.

Alemayehu, T., Ayenew, T., Kebede, S. (2006), “.Hydrogeochemical and lake level changes in the Ethiopian Rift”, Journal of Hydrology, 316 (1-4), pp. 290-300.

Alonso, B., Guillermo, T., and René, G. (2018), “Alternative approaches for estimating missing climate data: application to monthly precipitation records in South-Central Chile.", Forest Ecosystems. 5:28 https://doi.org/10.1186/s40663-018-0147-x.

Ayenew, T. (2002), "Recent changes in the level of Lake Abiyata, central main EthiopianRift", Hydrological Sciences Journal des Sciences Hydrologiques Vol. 47.

Ayenew, T. (2007), "Water management problems in the Ethiopian Rift: Challenges for Development.", Journal of African Earth Sciences 48: 222-236.

Belete, M., Bernd, D., \& Jackson, R. (2015), "Characterization of Water Level Variability of the Main Ethiopian Rift Valley Lakes" Hydrology, 3, 1; doi:10.3390/hydrology3010001.

Belihu, M., Abate, B., Tekleab, S., \& Bewket, W. (2018), "Hydro-meteorological trends in the Gidabo catchment of the Rift Valley Lakes Basin of Ethiopia.", Physics and Chemistry of the Earth, Parts A/B/C, 104, 84-101.

Bewketu, K. and Ayenew, T. (2015), "Hydrodynamics of Selected Ethiopian Rift Lakes", Civil and Environmental Research. ISSN 2224-5790 (Paper) ISSN 2225-0514 (Online) Vol.7, No.12.

Diro, G. T. Black, E. and Grimes, D.I.F. (2008), "Seasonal forecasting of Ethiopian Spring rains", Meteorol. Appl. V. 15, p. $73-83$.

Dinku, T.(2019).Challenges with availability and quality of climate data in Africa. Extreme Hydrology and Climate Variability. https://doi.org/10.1016/B978-0-12-815998-9.00007-5.

Ester, R. V. (2010), "Water Resources Management in the Central Rift Valley of Ethiopia”, MSc Thesis in Civil Engineering.UniversitatPolitècnica de Catalunya, Barcelona, Spain.

Farlie, D.J.G. (1971), "Rank Correlation Methods-Kendall”, Mg. J. R. Stat. Soc. Ser. General, 134, 682

Hare, F.K., (1983). "Climate and Desertification. Revised analysis (WMO-UNDP)", WCP-. Geneva, Switzerland, 44: $5-20$

Jury, M. (2014), "Mark R. Jury Southern Ethiopia Rift Valley lake fluctuations and climate “, Vol. 9(18), pp. 794805, DOI: $10.5897 /$ SRE2014.6062.

Kendall, MG. (1975)., "Rank Correlation Methods, 4th edition", Charles Griffin, London, U.K.

Khattak, M. S., Babel, M. S. \& Sharif, M. (2011), "Hydro-meteorological trends in the upper Indus River basin in Pakistan.”, Clim Res. 46, 103-119, https://doi.org/10.3354/cr00957.

Korecha, and Barnston, A.G.(2007), "Predictability of June-September Rainfall in Ethiopia”, Monthly weather review. V.135,p. 628-650.

Kumar, S., Merwade, V., Kam, J. \& Thurner, K. (2009), “.Streamflow trends in Indiana: Effects of long term persistence, precipitation and subsurface drains", J. Hydrol. 374, 171-183, https://doi.org/10.1016/j.jhydrol.2009.06.012.

Legess, D., Coulomb, C., Gasse, F. (2004), “.Analysis of the hydrologicalresponse of a tropical terminal lake, Lake Abiyata (Main Ethiopian Rift Valley) to changes in climate and human activities", J Hydrol Processes 18:487-504.

Legesse, D.; Ayenew, T. (2006), “Effect of improper water and land resource utilization on the central Main Ethiopian Rift lakes", Quat. Int., 148, 8-18.

Love, D., Uhlenbrook, S., Twomlow, S., Van der Zaag, P. (2010), "Changing hydroclimatic and discharge patterns in the northern Limpopo Basin, Zimbabwe.”, vol. 36(3), ISSN 0378-4738.

Lu, G.Y. and Wong, D.W. (2008), “An adaptive inverse-distance weighting spatial interpolation technique.", Comp.Geosc. J. 34 (9): 1044-1055.

Mann, HB. (1945), "Non-parametric test against trend”, Econometrica13, 245-259.

Maxime, S, Ricardo, O., Koen, M.J., Hartmut, G \& Jürgen, H.(2012), " Hydro-meteorological trends in semi-arid north-central Chile $\left(29-32^{\circ} \mathrm{S}\right)$ : water resources implications for a fragile Andean region,”, Hydrological Sciences Journal, 57:3, 479-495, DOI: 10.1080/02626667.2012.665607

Michael, K., Ida, W., Allan.R., and Henry K. (2012), "Estimating areal rainfall over Lake Victoria and its basin using ground-based and satellite data", Journal of Hydrology 464-465 401-411.

Ministry of Water Resources (MoWR.) (2010), "The Federal Democratic Republic of Ethiopia Ministry of Water Resources: Rift Valley Lakes Basin Integrated Resources Development Master Plan Study Project.", HalcrowGroup Limited and Generation Integrated Rural Development (GIRD) Consultants.

Raphael, M.,Tshimianga, D., Hughes, A., Evison, K. (2011), "Understanding hydrological processes and estimating model parameter values in large basins: the case of the Congo River basin", Proceedings of Symposium H01 held during IUGG 2011 in Melbourne, Australia.

Rift Valley Lakes Basin Authority (RVLBA) (2016), “Inventory Report of Water User in Ziway-Shalla Sub Basin 
in 2016, Water Resource Management Directorate (official Document)"

Seleshi, Y. and Zanke, U. (2004), "Recent changes in rainfall and rainy days in Ethiopia. International ", Journal of Climatology 24, 973-983.

Sen, P.K. (1968), “Estimates of the regression coefficient based on Kendall's tau”, J. Am. Stat. Assoc. 63, 13791389.

Seyoum, W., M., Adam, M., \& Michael, C. (2015), “.Understanding the relative impacts of natural processes and human activities on the hydrology of the Central Rift Valley lakes, East Africa”, Hydrol.Process.Department of Geology, University of Georgia, Athens, GA, USA.

Suryabhagavan, K.V. (2017), " GIS-based climate variability and drought characterization in Ethiopia over three decades School of Earth Sciences", Addis Ababa University, P.O. Box 1176, Addis Ababa, Ethiopia. Weather and Climate Extremes 15 11-23 http://dx.doi.org/10.1016/j.wace.2016.11.005.

Teegavarapu, RSV. (2009), "Estimation of missing precipitation records integrating surface interpolation techniques and spatio-temporal association rules", J Hydroinf 11(2):133-146.

Tekleab, S., Mohamed, Y. and Uhlenbrook, S. (2013), "Hydro-climatic trends in the Abay/upper Blue Nile basin, Ethiopia", Physics and Chemistry of the Earth, Parts A/B/C, 61, pp.32-42.

Takele, G., Maurice, N., Benedict, M., and Fiseha, B.(2019). "Comparative Assessment of the Effect of Climate Change and Human Activities on Streamflow Regimes in Central Rift Valley Basin, Ethiopia." American Journal of Water Resources, vol. 7, no. 1: 23-29. doi: 10.12691/ajwr-7-1-4.

Tamrat L M. (2018), "Spatio-Temporal Analysis of Rainfall Variability and Meteorological Drought: A Case Study in Bilate River Basin, Southern Rift Valley, Ethiopia”, . Int J Environ Sci Nat Res. 14(4): 555891. DOI: 10.19080/IJESNR.2018.14.555891. 079.

Tesemma, Z.K., Mohamed, Y.A., Steenhuis, T.S.(2010), "Trends in rainfall and runoff in the Blue Nile Basin: 1964-2003”, Hydrol. Process.. http://dx.doi.org/10.1002/ hyp.7893.

Teyso, T.A. and Anjulo, A. (2016), "Spatio-temporal Variability and Trends of Rainfall and Temperature Over GamoGofa Zone, Ethiopia.Directorate of Climate Change Research", Ethiopian Environment and Forest Research Institute; DOI: 10.9734/JSRR/2016/28667.

Wagesho, N.; Goel, N.K.; Jain, M.K. (2012), "Investigation of non-stationarity in hydro-climatic variables at Rift Valley lakes basin of Ethiopia.", J. Hydrol., 444-445, 113-133.

Wakachala, F.M., Z.W. Shilenje, J. Nguyo, S. Shaka and W. Apondo. (2015), “ Statistical Patterns of Rainfall Variability in the Great Rift Valley of Kenya", . Journal of Environmental \& Agricultural Sciences. 5:17-26.

Yilinuer, A., Jilili, A., Balati, M., Bilal, E., Michael, G. (2020), "Innovative Trend Analysis of Precipitation in the Lake Issyk-Kul Basin”, Kyrgyzstan. Atmosphere 2020, 11, 332; doi: 10.3390/atmos11040332.

Zannat, F., Islam, A. R. M., \& Rahman, M. A. (2019)," Spatiotemporal variability of rainfall linked to ground water level under changing climate in northwestern region, Bangladesh", Eur. J. Geosc. 2019, 01(01) 35 56.

Zinabu G. M. \& Elias D. (1989)," Water resources and fisheries management in the Ethiopian rift-valley lakes", SINET: Ethiopian J. Sci. 12, 95-109. 